\title{
Effect of prohexadione calcium on vegetative growth, yield and scab development on 'Sinap Orlovskii' apple trees
}

\author{
Natalia Kashirskaya, Andrei Kuzin, and Anna Kochkina \\ I.V. Michurin Federal Scientific Centre, 393774 Michurinsk, Russian Federation
}

\begin{abstract}
There are many apple orchards in the Russian Federation where trees were trained with volumetric canopies; the vigor of these canopies must be suppressed. Prohexadione calcium (calcium 3-hydroxy-5-oxo-4propionyl-cyclohex-3-enecarboxylate) was developed to inhibit the gibberellins biosynthesis to reduce vegetative growth. The study was done in the commercial orchard of "Planeta sadov" LLC in Michurinck district of Tambov Region $\left(53^{\circ} 02^{\prime} 11.9\right.$ "N 40²9'29.9 "E). This research was aimed to evaluate the influence of prohexadione calcium on the length of one-year shoot growth, yield, and scab development on trees of vigorous apple cultivar 'Sinap Orlovskii,' planted 6 x 4 m (418 tr. ha-1). After $1.25+$ $1.25 \mathrm{~g}$ ha-1 prohexadione calcium double treatment, the length of one-year shoots was 1.96 (2019) and 1.60 (2020) times less than Control 1 (without prohexadione calcium application and hand pruning) and 2,00 times less than in hand pruning treatment. The application of prohexadione calcium inhibited apple tree height and reduced the average height growth rate by $10.7 \%$ (2019) and $17.0 \%$ (2020). Growth retardant treatments stimulated significant yield increases and improved the commercial value of fruits. The enhance of scab protection improved under the influence of prohexadione calcium treatments. The application of growth retardant increased the alternate bearing index.
\end{abstract}

\section{Introduction}

Prohexadione calcium (Pro-Ca) belongs to a class of plant growth retardants cyclohexanetriones [1] and inhibits biosynthesis of gibberellins in the range GA1-GA20 [2, $3]$. Because of this, the growth regulator has a broad spectrum of action: the treatments stimulate increased fruit set and enhance the resistance to such dangerous disease like fire blight (Erwinia amylovora) [4, 5]. There are also reports that Pro-Ca treatments decreased scab (Venturia inaequalis) development [6]. It is possible because the application of Pro-Ca increases the concentration of specific flavonoids [8].

Climate change in Central Russia is increasing (warm winters, often thaws, etc.) and these changes in weather conditions provoke the enhancement of apple tree vegetative growth [9]. The light transmission becomes insufficient due to excessive vegetative growth (because of too many branches), stimulating disease development, making more expensive

*Corresponding author: andrey.kuzin1967@yandex.ru 
and challenging pruning, and finally reducing the yield and fruit quality [10]. Pro-Ca's application reduces the internode length of one-year shoots but does not decrease their number [11]. The number of leaves and their area do not diminish, which is very important for yield. Pro-Ca is relatively widely used in the South of Russia; the treatments stimulated a decrease of one-year shoot length and increased yield, mainly because of reducing alternate bearing [12]. But the plant reaction on growth retardant applications strongly varied among the different cultivars $[13,14]$. Also, the impact of treatments depends on rootstocks [15].

An essential feature of Pro-Ca action is also the inhibition ethylene biosynthesis, which increases yield because of reducing abortion of fruitlets [16]. The significant aftereffect of Pro-Ca application is not only a positive impact on vegetative growth decrease and yield stabilization. It also improves fruit quality [17]. One of the reasons for yield increase because of Pro-Ca treatment might enhance potassium and calcium concentrations in pome fruits [18]. A sufficient potassium level is required for high yield [19]. And yet, ample fruit calcium status is the crucial factor of their storability [20], and it has a special significance for cv. 'Sinap Orlovskii,' because its fruits usually have insufficient calcium concentration and susceptible to bitter pit because of this.

This study aimed to research the influence of the growth retardant Pro-Ca on vegetative growth, yield, and opportunity for scab infestation reducing in the apple orchard of cv. 'Sinap Orlovskii' in the conditions of Central Russia.

\section{Materials and Methods}

The study was done in the commercial orchard of "Planeta sadov" LLC in Michurinsk district of Tambov region $\left(53^{\circ} 02^{\prime} 11.9\right.$ "N 40²9'29.9 "E) in 2019-20. The orchard was planted in 2012 , $6 \times 4 \mathrm{~m}$ (417 tr. ha $\left.{ }^{-1}\right)$ without irrigation. Trees were trained to a sparsetiered system (trees had three tiers of skeletal branches on the leader), cultivar 'Sinap Orlovskii', grafted on B118. REGALIS ${ }^{\circledR}$ PLUS was used as a source of Pro-Ca $-10 \% \mathrm{w} / \mathrm{w}$ prohexadione, water-dispersible granules. Experiment design: 1. Control 1 (without hand pruning and Pro-Ca application); 2. Hand Pruning; 3. Single treatment $-250 \mathrm{~g} \mathrm{ha}^{-1}$ (oneyear shoot length approximately $5 \mathrm{~cm}$ ); 4 . Double treatment $125+75 \mathrm{~g} \mathrm{ha}^{-1} ; 4.125+125 \mathrm{~g}$ $\mathrm{ha}^{-1}$ (first application - one-year shoot length approximately $5 \mathrm{~cm}$, second application -4 weeks after the first one). The experiments were arranged in four replication for each treatment, the number of trees in each replication - 50. For evaluation of biological efficiency of the plant protection system against scab, we used Control 2 without treatments both protection products against scab and Pro-Ca - four replications, number of trees in each replication -5 . Protection system against scab: copper chloride $400 \mathrm{~g} \mathrm{~L}^{-1}\left(5.0 \mathrm{~L} \mathrm{ha}^{-1}\right)$; $700 \mathrm{~g} \mathrm{~kg}-1$ metiram $\left(2.5 \mathrm{~kg} \mathrm{ha}^{-1}\right)$; dithianon $125 \mathrm{~g} \mathrm{~L}^{-1}\left(0.7 \mathrm{~L} \mathrm{ha}^{-1}\right)$; difenoconazole $50 \mathrm{~g} \mathrm{~L}^{-1}$ + flutriafol $30 \mathrm{~g} \mathrm{~L}^{-1}\left(1.0 \mathrm{~L} \mathrm{ha}^{-1}\right)$; difenoconazole $250 \mathrm{~g} \mathrm{~L}^{-1}\left(0.3 \mathrm{~L} \mathrm{ha}^{-1}\right)$; trifloxystrobin $500 \mathrm{~g}$ $\mathrm{kg}^{-1}\left(0.14 \mathrm{~kg} \mathrm{ha}^{-1}\right)$. Records - length of one-year shoots, the height of trees, scab damages. Scab damages were determined by the area and number of lesions on the surface of leaves and fruits and evaluated in a point scale: leaves: $0=$ no scab symptom; $1=$ sporadic small spots, up to $1 \%$ of leaf surface; $2=$ small or average size lesions, $1-10 \%$ of leaf surface; $3=$ large or many small spots, $11-25 \%$ of leaf surface; $4=$ large lesions with a dark coating of fungal sporulation, $25-50 \%$ of leaf surface; $5=$ large spots with fungal sporulation, more than $50 \%$ of the leaf surface; fruits: $0=$ no scab symptom; $1=$ sporadic small spots $(1$ or 2 per unit), non-corky; $2=$ small size lesions, corky, up to $5 \%$ of leaf surface; $3=2-3$ small spots up to $5 \mathrm{~mm}$ diameter, with faint sporulation, $6-25 \%$ fruit surface; $4=$ many large lesions $(5-20 \mathrm{~mm})$ with a dark coating of fungal sporulation, cracks are possible, $26-50 \%$ of fruit surface; 5 = large spots with fungal sporulation, deep cracks, more than $50 \%$ of the 
fruit surface. Abbott's formula was used to calculate the biological efficiency of protection against scab [21]:

$$
C=\frac{X-Y}{X} \times 100
$$

where $\mathrm{C}$ is the biological efficiency (percent control)

$X$ is the prevalence of scab in the untreated control

$Y$ is the prevalence of scab in the treated plot.

We assessed the commercial quality of the fruits on size and scab damage presence according to RF standards [22]. Alternate bearing index (ABI) was calculated as stated in [23]:

$$
A B I=\frac{\text { year } 1 \text { yield }- \text { year } 2 \text { yield }}{\text { year } 1 \text { yield }+ \text { year } 2 \text { yield }}
$$

Where $\mathrm{ABI}=0$ - is no alternate bearing, and $\mathrm{ABI}=1$ is complete alternate bearing. Statistical analysis was done according to Fisher's method. We calculated the Lowest Significant Difference (LSD) between various treatments by $\mathrm{P}<0.05$. The differences were higher than the computed LSD value were considered significant [24].

\section{Results and Discussion}

The weather conditions during in both years of the research differed from each other, the many-years average on precipitation intensity and day average air temperatures during the growing seasons. The daily air average temperature was $+2.4 \ldots+3.5^{\circ} \mathrm{C}$ higher than the many-year average. The amount of precipitation was only $58.6 \%$ from usual in April-June of 2019. In the next 2020, the amount of precipitation was 1.4 times more compare to the average of 50 years. The temperature was on the same level as it was usual in these three months in 2020. In July-August of 2019, the air temperature and precipitation were close to the many-years average. The amount of precipitation was only $39.2 \%$ from regular during three months.

The Pro-Ca treatments had a significant effect on reducing the annual shoot growth rate in 2019 and 2020 (Figures 1 and 2).
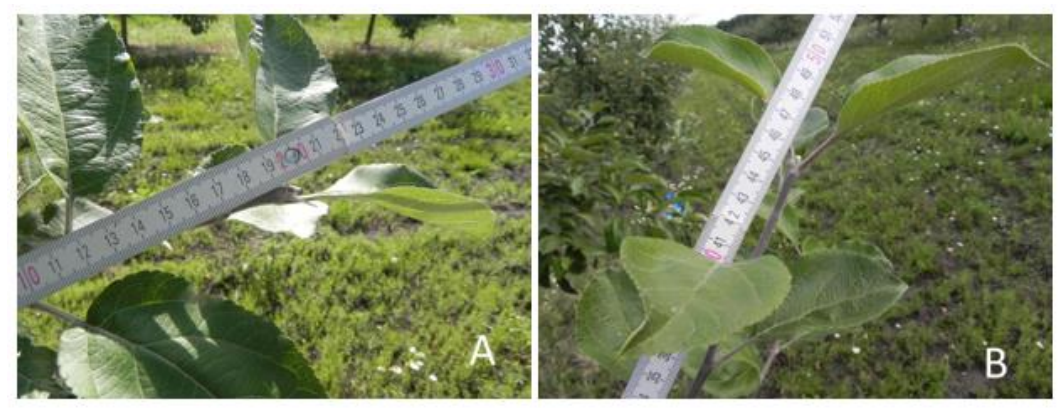

Fig. 1. The influence of Pro-Ca on the length of one-year shoot growth in treatments $125+125 \mathrm{~g}$ ha- 1 (A) compare to hand pruning (B) in 2020.

All Pro-Ca treatments stimulated vegetative growth reduction in 2019. The value of annual growth rate in Control 1 and Hand pruning treatment had no significant differences. But, after Pro-Ca sprayings, this value was considerably less. The number of Pro-Ca sprayings and application rate had no substantial effect on the vegetative growth of 'Sinap Orlovskii'/B118 trees this year. 
The most considerable value of the average annual growth rate was in the treatment with hand pruning (significantly more than in Control 1). There are some reports that hand pruning stimulated tree growth activity $[24,25]$. The higher amount of precipitation also encouraged the growth of trees in April-June 2020. The least annual growth rate (significantly lower than in the other treatments) was in the treatment $125+125 \mathrm{~g} \mathrm{ha}^{-1}$ Pro$\mathrm{Ca}$ in 2020. It confirms the hypothesis about the essential difference in cultivar response on Pro-Ca treatment: on the other cultivars (Bogatyr, Rozhdestvenskoye, and Zhigulevskoye), the $125+75 \mathrm{~g} \mathrm{ha}^{-1}$ treatment has the best result in very similar weather and soil conditions [13].

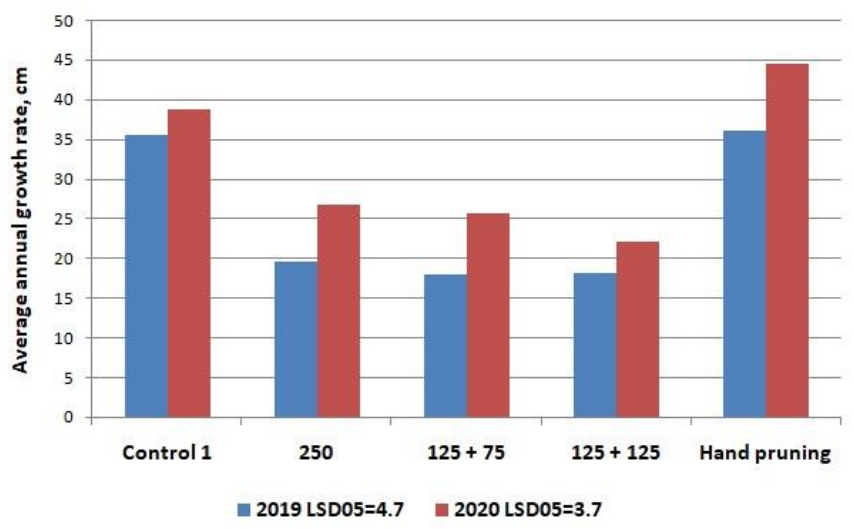

Fig.2. The effect of Pr-Ca on the value of average annual growth rate.

The tree height is an important parameter, partly defining the harvest cost because lower tree harvesting needs less labor time [27]. We suppose that the Pro-Ca also retards the tree height growth. The Pro-Ca application did not significantly affect tree height growth in 2019 (Fig. 3). Never the less, we can see the tendency that in all of the Pro-Ca treatments, the tree height was lower than in Control 1 and hand pruning treatment.

The effect of Pro-Ca applications was much more on the background of general vegetative growth enhance in 2020 . In all treatments with the growth retardant application, the tree height was considerably less than in hand pruning treatment. There were no significant differences between the Pro-Ca treatments and Control 1 also in this year. Never the less, we can see the apparent tendency of the growth retarding under the effect of Pro$\mathrm{Ca}$. Similar results are reported from other research where it is noted that the retarding of the tree height growth is correlated with lower canopy volume [28]. The differences in tree height increase (HID) confirm that Pro-Ca application in all treatments retarded the tree height growth; the most considerable effect was in the treatment $125+125 \mathrm{~g} \mathrm{ha}^{-1}$. 


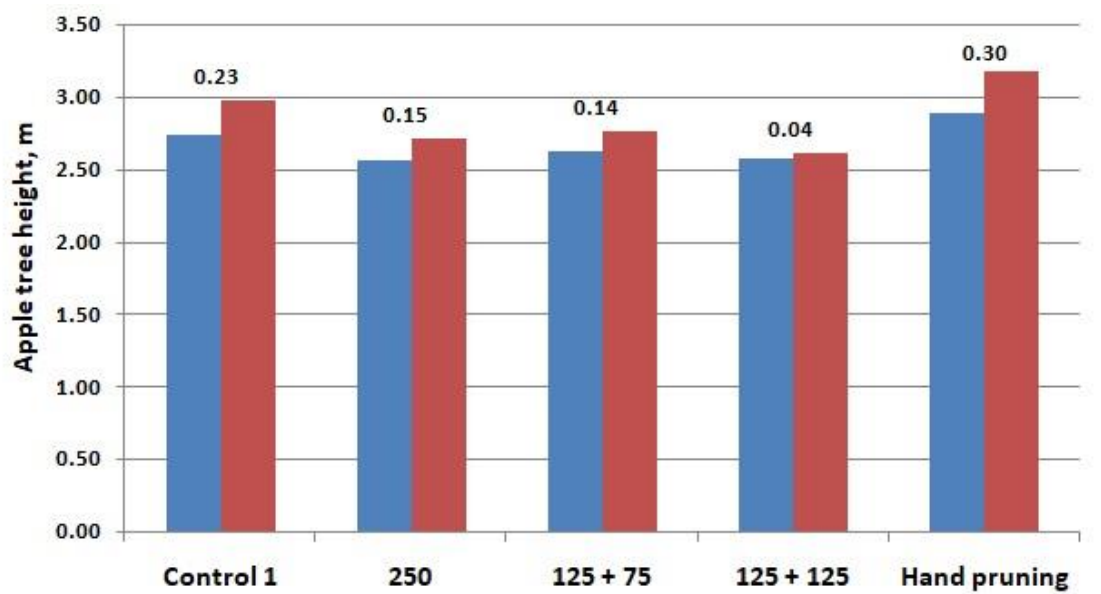

2019 LSD05=0.34 2020 LSD05 $=0.39$ HID LSD05 $=0.05$

Fig. 3. The effect of growth retardant Pro-Ca on tree height and its annual increase of cv. 'Sinap Orlovskii'/B118 trees (above the chart columns).

Apple scab is one of the most dangerous diseases, which can considerably decrease the amount and commercial value of yield, leading to significant losses [29]. The development of scab depends on air humidity, and it is going stronger after heavy rainfall. Because of this, we noted more intensive scab development in 2020. The biological efficiency of the used protection system against scab increased when Pro-Ca was applied (Table 1). The plant protection was not done in Control 2 (without plan protection against scab and Pro-Ca application), and the scab infestation of leaves and fruits was $18.6 \%$ and $2.1 \%$ (2019), $27.1 \%$, and $29.4 \%$ (2020), respectively.

Table 1. The effect of Pro-Ca application on scab development and protection system biological efficiency

\begin{tabular}{|c|c|c|c|c|c|c|c|c|}
\hline \multirow{3}{*}{ Treatment } & \multicolumn{4}{|c|}{ Scab development, \% } & \multicolumn{4}{c|}{ Biological efficiency, \% } \\
\cline { 2 - 9 } & \multicolumn{2}{|c|}{2019} & \multicolumn{2}{|c|}{2020} & \multicolumn{2}{c|}{2019} & \multicolumn{2}{c|}{2020} \\
\cline { 2 - 9 } & Leaves & Fruits & Leaves & Fruits & Leaves & Fruits & Leaves & Fruits \\
\hline Control 2 & 18.6 & 2.1 & 27.1 & 29.4 & - & - & - & - \\
\hline 250 & 1.3 & 0.4 & 4.7 & 4.2 & 92.8 & 80.2 & 82.6 & 85.7 \\
\hline $250+75$ & 1.2 & 0.3 & 4.5 & 3.8 & 93.8 & 84.9 & 83.4 & 87.1 \\
\hline $125+125$ & 1.0 & 0.1 & 4.2 & 3.5 & 94.9 & 93.9 & 84.5 & 88.1 \\
\hline Hand pruning & 1.9 & 0.4 & 5.9 & 5.6 & 90.0 & 79.2 & 78.2 & 80.9 \\
\hline
\end{tabular}

The most scab development on leaves and fruits was in the $250 \mathrm{~g} \mathrm{ha}^{-1}$ Pro-Ca treatment in $2019(1.3 \%$ and $0.4 \%)$. In the next year, the scab damages wer also high in this treatment $-4.7 \%$ and $4.2 \%$, but was less than in hand pruning treatment $(5.9 \%$ and $5.6 \%)$. The least scab damage was in $125 \mathrm{~g} \mathrm{ha}^{-1}$ treatment $-1.0 \%$ and $0.1 \%$ (2019) and $4.2 \%$ and $3.5 \%$ (2020). The decrease in scab development provided the increase in biological efficiency $94.9 \%$ and $93.9 \%$ (2019), and $84.5 \%$ and $88.1 \%$ (2020) in this treatment. Such an effect of Pro-Ca application makes it possible to decrease the pesticide load on agrocenosis, but this problem must be studied.

The main parameters to evaluate fruit production efficiency are yield and fruit quality their commercial value. These parameters are sum up the outcome of fruit growing. The obtained results demonstrated the high efficiency of Pro-Ca (Table 2). 
Table 2. Effect of Pro-Ca application on yield and commercial qualities 'Sinap Orlovskii' fruits.

\begin{tabular}{|c|c|c|c|c|c|c|c|c|c|}
\hline \multirow{3}{*}{ Treatment } & \multirow{2}{*}{$\begin{array}{l}\text { Yield } \\
\text { kg tr. }{ }^{-1}\end{array}$} & \multicolumn{3}{|c|}{ Commercial grade, $\%$} & \multirow{2}{*}{$\begin{array}{l}\text { Yield } \\
\text { kg tr. }^{-1}\end{array}$} & \multicolumn{3}{|c|}{ Commercial grade, $\%$} & \multirow{2}{*}{$\mathrm{ABI}$} \\
\hline & & I & II & $\begin{array}{c}\text { Non- } \\
\text { standard }\end{array}$ & & $\mathrm{I}$ & II & Non-standard & \\
\hline & \multicolumn{4}{|c|}{2019} & \multicolumn{4}{|c|}{2020} & \\
\hline Control 1 & 14.3 & 44 & 39 & 17 & 19.1 & 37 & 46 & 17 & 0.144 \\
\hline 250 & 16.3 & 83 & 12 & 5 & 22.7 & 82 & 14 & 4 & 0.164 \\
\hline $125+75$ & 16.2 & 79 & 18 & 3 & 25.2 & 77 & 16 & 7 & 0.217 \\
\hline $125+125$ & 16.4 & 80 & 15 & 5 & 27.4 & 75 & 20 & 5 & 0.251 \\
\hline Hand pruning & 16.0 & 75 & 20 & 5 & 17.2 & 70 & 25 & 5 & 0.036 \\
\hline $\mathrm{LSD}_{05}$ & 1.5 & - & - & - & 1.8 & - & - & - & 0.034 \\
\hline
\end{tabular}

Pro-ca applications significantly enhance the fruit set in the treatments with retardant use compared to Control 1 in 2019. The yield was also high in the hand pruning treatment, and the productivity did not have considerable differences with Pro-Ca treatments. The most commercial value of fruits was in the $125+125 \mathrm{~g} \mathrm{ha}^{-1}$ Pro-Ca treatment. The least value was noted in Control 1 (without hand pruning and Pro-Ca applications). We also did not see the significant differences in this year between the treatments with the growth retardant applications and hand pruning.

In 2020, the hand pruning treatment yield was on the level of the previous year, but in all of the other treatments, including Control 1, the productivity enhanced. The possible reason of this could be the strengthening of the vegetative growth in 2020 compared to 2019. Relatively strong pruning can stimulate growth processes, and it could lead to the redistribution of assimilates in favor of vegetative growth ensuring [30].

The largest yield was in $125+125 \mathrm{~g} \mathrm{ha}^{-1}$ Pro-Ca treatment in 2020 . It was considerably more than in all other treatments of our study, including the rest Pro-Ca treatments. The most commercial value of fruits was in the $250 \mathrm{~g} \mathrm{ha}^{-1} \mathrm{Pro}-\mathrm{Ca}$ (in this treatment was the least part of non-standard fruits). Pro-Ca's application stimulated the yield increase and commercial quality of fruits manly due to inhibiting the one-year shoot vegetative growth. Similar results were also obtained in some other studies, confirming our research result [16, 17, 31]. Simultaneously, there are some reports where authors noted the Pro-Ca applications did not affect yield [32,33]. But in the last-mentioned articles, Pro-Ca was applied in combination with growth regulators like gibberellins and ethephon; perhaps it changed Pro-Ca's action.

The Pro-Ca application in our research significantly increased in the ABI value, although its magnitude was low. It isn't easy to make a clear conclusion based on biennial data. The hand pruning significantly decreased the ABI, which is noted in many reports [34]. The Pro-Ca application significantly impacts plant physiological status and its hormonal balance [35]. There some reports that the use of Pro-Ca did not increase ABI during long-term applications [35].

Moreover, it is noted that the ABI decreased in some cases [12]. However, as we have already stated in this paper, the Pro-Ca depends on the weather conditions and cultivar features to have a different impact under various circumstances. This problem also requires further investigation. There are many reports that Pro-Ca stimulates a considerable increase in fruit set $[4,37]$. Further research must also be done for the combined use of Pro-Ca and other growth regulators, first of all, chemical thinners.

\section{Conclusions}

The Pro-Ca applications stimulated a considerable decrease in the average annual growth rate of one-year shoots and tree height. The yield increased in treatments with Pro-Ca 
application. The most significant effect was in the treatment $125+125 \mathrm{~g} \mathrm{ha}^{-1}$. The sprayings with Pro-Ca enhanced the biological efficiency of the used plant protection system against scab. The ABI increased in treatment where Pro-Ca was applied, which confirms the need for Pro-Ca combinations with thinners. These problems need further research.

\section{References}

1. W.K.E. Rademacher, D.L. Temple-Smith, and P. Hedden, 571 (1992)

2. W.K.E. Rademacher, Acta Hortic, 394, 57 (1995)

3. W.K.E. Rademacher, Annu. Rev. Plant Physiol, 51, 501 (2000)

4. R. Medjdoub, J. Val, and A. Blanco, Sci. Hort, 101(3), 243 (2004)

5. L. Asín, S. Alegre, R. Montserrat, Sci. Hort, 113(2), 142 (2007)

6. G. Costa, F. Spinelly, E. Sabatini, and W. Rademacher, Acta Hortic, 653, 133 (2004)

7. W. Feucht, D. Treutter, and P. Schwab, Zeit. Pflanzenkrank. Pflanzensch. / J. Plant Dis. Prot, 105(4), 394 (1998)

8. S. Römmelt, D. Treutter, W. Rademacher, and Speakman, Acta Hortic, 498, 601 (1999)

9. E. Tsukanova, E. Tkachev, IOP Conf. Series: Earth and Environmental Science, 226 (2019)

10. S.S. Miller, T. Tworkoski, PGRSA Quarterly, 31(1), 8 (2003)

11. M.D. Pasa, J.C. Fachinello, H.F. da Rosa Júnior,É.DeFranceschi, F.G. Herter, C.P. da Silva, and A.L.K. de Souza, CAST, 22(1), 40 (2016)

12. V.P. Popova, T.G. Fomenko, L.D. Chalaya, Hort, Vitic, 3, 31 (2013).

13. N.Ya. Kashirskaya, A.A. Skrylev, A.V. Solovjev, A.M. Kochkina, Hort. Vitic, 3, 54 (2018)

14. J.C. Fachinello, T.L. Robinson, Acta Hortic, 727, 215 (2017)

15. R.M. Grasweller, and D.E. Smith, Acta Hortic, 1177, 107 (2017)

16. W, Rademacher, F. Spinelly, and G. Costa, Acta Hortic, 727, 97 (2006)

17. A.P. Mata, J. Val, and A. Blanco, J. Hortic. Sci. Biotech, 81(6), 965 (2006)

18. M. Lal, M.M. Mir, U. Igbal, and A. Kumar, Int. J. Chem. Stud, 8(1), 256 (2020)

19. A.I. Kuzin, N.Ya. Kashirskaya, A.M. Kochkina, and A.V. Kushner, Plants, 9(10), 1366 (2020)

20. M.C. Saure, Sci. Hort, 105(1), 65 (2005)

21. J.L. Capinera, Encyclopedia of entomology, 2 (2008)

22. GOST 34314-2017 Fresh apples for retail. Specifications (2021)

23. S.P. Monselise, and E.E. Goldscmidt, Hortic, Rew, 4, 128 (1982)

24. B.A. Dospekhov, Methodology of Field Experiences, 1 (1985)

25. A. Mika, Hortic. Rew, 8, 337 (1986)

26. D. Tomasi, F. Gaiotti, D. Petoumenou, L. Lovat, N. Belfiore, D. Boscaro, and G. Main, Agronomy, 10, 1509 (2020)

27. J.A.Yuri, M. Ibara-Romero, J.L. Vásquez, V. Lepe, J. Gonzales-Talice, A. Del Polo, Sci. Hortic, 130(1), 191 (2011) 
28. M.Ģetingbaş, S. Butar, A. Atasay, M. İşçi, and H. Koçal, J. Appl. Bot. Food Qual, 88, 259 (2015)

29. G. Agrios, Plant pathology. $5^{\text {th }}$ Edition, 952 (2005)

30. P.S. Gelfandbein, Pruning and training of fruit trees, 384

31. J.L. Petri, G. Berenhauser-Leite, F.J. Hawerroth, and C. Basso, Acta Hortic, 903, (2011)

32. C. Duyvelshoff, J.A. Cline, Sci. Hortic, 151, 128 (2013)

33. S.S. Miller, HortTechnology, 17(4), 523 (2007)

34. T.L. Robinson, L.I. Dominguez, and F, Acosta, Acta Hortic, 1130, 257 (2016)

35. H. Ramirez, S. Alonso and A. Benavides, Acta Hortic, 727, 117 (2006)

36. A.N. Atay, and F. Koyuncu, J. Hortic. Res, 25(1), 47 (2017)

37. D.W. Green, Hortscience, 42(6), 1361 (2007) 